\title{
Estratégias de comunicação na ambiência
} digital:

\section{Mapeamento do quadro conceitual}

\section{Communication strategies in digital environment: Conceptual framework maping}

\section{Por Taís Steffenello Ghisleni e Graziela Frainer Knoll}

\section{Introdução}

Ao longo dos anos, a internet constituiu-se como uma rede infinita de mensagens, produzidas e reproduzidas a cada momento, de modo não uniforme, já que não há como prever o caminho das interações ou das possibilidades estratégicas oferecidas pelas diferentes plataformas. Conforme Bueno (2003), esse aspecto pode implicar, do ponto de vista das organizações e marcas, certas dificuldades e desafios à medida que os formatos, o conteúdo e a linguagem renovam-se continuamente, provocando adaptações na comunicação publicitária.

A comunicação na ambiência digital se caracteriza pela interação e pela interatividade. A interação, analisada sob o ponto de vista de Thompson (2008), que enfoca os processos de comunicação das mídias, demonstra que o desenvolvimento dos meios de comunicação afetou, ao longo da história da civilização, todas as formas como a informação é produzida e recebida, podendo ser mediada ou não por canais tecnológicos. Já a interatividade, segundo McMillan (2002), é um conceito necessariamente ligado à tecnologia, pois consiste na característica das interações mediadas por dispositivos tecnológicos. Desse modo, afeta a experiência do usuário ao conceber novos meios e processos interativos.

Pensando na gestão da comunicação, Lupetti (2007) explica que estratégia se refere às ações planejadas e executadas a partir da análise ambiental interna e externa, de análise dos pontos fortes e fracos da organização, das ameaças e das oportunidades do mercado, do diagnóstico de comunicação, dos públicos envolvidos, dos objetivos de comunicação determinados e dos posicionamentos estratégicos e específico da gestão da comunicação (LUPETTI, 2007, p. 89). 
Para empresas e marcas, são necessárias ações planejadas, alinhadas com suas estratégias e seu posicionamento, pois a "presença digital representa a existência de uma entidade nas mídias digitais e sociais" (STRUTZEL, 2015, p.87). Dessa maneira, são elaboradas e empreendidas diferentes estratégias de comunicação.

O objetivo deste artigo é discutir a respeito das estratégias de comunicação existentes centradas na ambiência digital. Para tanto, serão realizados os seguintes objetivos específicos: mapear o quadro conceitual de estratégias de comunicação e de marketing e problematizar a necessidade da atualização de conceitos nessa área.

"Embora as mídias sociais representem um fenômeno relativamente recente, sobretudo se levarmos em conta a sua repercussão (análise, pesquisa e estudo) na Academia, já é possível encontrar uma série de obras relevantes sobre o tema" (BUENO, 2015, p. 209). No entanto, as obras já publicadas enfatizam as estratégias com foco nas ações desenvolvidas pelas organizações, e não no quadro conceitual teórico, que é o foco desta pesquisa.

\section{Cenários da web e evolução da comunicação}

As mudanças oportunizadas pelas tecnologias digitais e as várias transformações da Web e do consumidor foram classificadas pela O’Reilly Media em três ondas conhecidas como Web 1.0, Web 2.0 e Web 3.0 (GABRIEL, 2010), e a esses cenários já somamos outra vertente chamada 4.0 (TURCHI, 2018), ainda em desenvolvimento. Gabriel (2010) explica que os termos utilizados não sugerem novas versões para a web, mas constituem uma divisão didática, relacionada mais com o comportamento dos usuários do que com as tecnologias em si (Quadro 1).

Quadro 1 - Cenários da Web

\begin{tabular}{|l|l|l|l|}
\hline Web 1.0 & Web 2.0 & Web 3.0 & Web 4.0 \\
\hline - Estática & - Participativa & - Web semântica & - Cidades inteligentes \\
-Consumo de informações & - Interação focada em & - Aperfeiçoamento & - Bolhas da Internet \\
- Pouca interação & mídias sociais (Orkut, & contínuo & - Possíveis restrições de \\
- Configura-se de grandes & MySpace, Tumblr, blog) & - Inteligência artificial & uso \\
grupos para o usuário & - Produção de conteúdo & - Convergência & tecnológica \\
& - Armazenamento em & - Convergência midiática & \\
& nuvem & (crossmídia, transmídia) & \\
& - Dispositivos portáteis & - Usuário como & transformador e \\
& & (re)programador das & \\
& & tecnologias & \\
\hline
\end{tabular}

Fonte: Elaborado a partir de Gabriel (2010), Strauss e Frost (2012) e Turchi (2018). 
No cenário 1.0, "uma vez que o controle do conteúdo e das relações permanece nas mãos do emissor, a maioria de suas propostas de interatividade e diálogos com o usuário não passa de ações que simulam a participação" (SAAD, 2008, p.155). Portanto, a web 1.0 "constitui-se de forma pouco interativa, tradicional e oferece a possibilidade de comunicação unidirecional com a sociedade" (BARICHELLO et. al., 2013, p. 137).

"Embora a web 1.0 conectasse pessoas às redes de computador, as tecnologias da web 2.0 também conectam pessoas entre si” (STRAUSS; FROST, 2012, p. 11). A diferença de cenário encontra-se na participação do usuário, que passou a ser reconhecido "como o principal potencializador e propagador da mensagem para outros grupos de pessoas. As mensagens são baseadas em experiências e formulações de opiniões projetadas para causarem reações” (SAAD, 2008, p. 156).

De acordo com Saad (2008, p. 149), “a web 2.0 potencializa a ação do usuário na rede por meio da oferta, quase sempre gratuita, de ferramentas que permitem a expressão e o compartilhamento com outros usuários de opiniões, criações, desejos, reclamações, enfim, qualquer forma de comunicação interpessoal". Assim, o termo aparece como uma tendência de troca de informações e colaboração entre internautas e plataformas virtuais. As bases encontramse no princípio da construção coletiva e na valorização da participação dos sujeitos.

Na configuração da Web 2.0, "a mensagem passa a ter caráter muito especial, deixando de ser só um anúncio de convencimento para dar lugar à opinião de alguém que vivenciou uma experiência e tem algo a dizer sobre isso" (SAAD, 2008, p. 156). Entra em cena o conteúdo gerado pelo usuário, compartilhamento, diálogos e conversações. Barichello et. al. (2013, p. 138) ressaltam que "por meio das mídias sociais digitais, o interagente deseja comentar, criticar, compartilhar, recomendar e/ou modificar determinado material oferecido na rede pelas empresas ${ }^{1}$.

Com a Web 2.0, a internet ingressou em um período no qual a palavra de destaque foi a interatividade, já que a rede mundial de computadores está sendo feita por gente e não apenas por sistemas operacionais ou conglomerados corporativos. Outra mudança visível se deu no foco, que passou da publicação para a participação e com isso passou-se a valorizar, cada vez mais, os espaços para interação mútua: o diálogo, o trabalho cooperativo, e a construção coletiva do comum.

\footnotetext{
${ }^{1}$ As mídias sociais são bons canais de comunicação, tanto para publicar conteúdos quanto compartilhar conhecimento. Também facilitam a procura por materiais já publicados utilizando ferramentas e buscas (STRUTZEL, 2015). O conceito não será ampliado, pois nosso foco encontra-se apenas nos sites.
} 


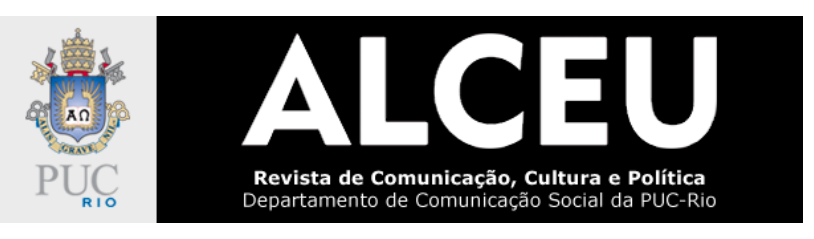

Strauss e Frost (2012) relatam que a web 2.0 contextualizou novos desafios e oportunidades para os profissionais de marketing. Entre eles estão: a transferência do poder dos vendedores para os compradores; o uso do marketing de atração (inbound marketing), ou seja, o produto/serviço é facilmente encontrado no mundo online, e com isso deixa de interromper os clientes com ações tradicionais; o engajamento (envolvimento emocional e cognitivo dos clientes); e ainda as métricas das mídias sociais. Os autores também apresentam outros elementos-chave do cenário da web 2.0, como o amadurecimento da adesão à internet (o uso intenso da web e do e-mail já é uma atividade corriqueira) e das vendas a varejo online; os mecanismos de busca que atualmente são mecanismos de reputação; o conteúdo como um fator soberano; a integração entre estratégias online e off-line (marketing multicanal); a possibilidade de velocidade rápida de acesso à internet; o papel do capital intelectual (profissionais com know-how); e a cauda longa, que explica como a computação e o armazenamento de baixo custo viabilizam a venda de pequenas quantidades de um grande número de produtos online com grandes receitas.

Também chamada de Web 3.0, a Web semântica é o que vivemos hoje, uma Web na qual "as informações são trabalhadas pelos grandes líderes da web, como Google, Facebook e outros, que detêm uma série de dados expostos pelos internautas no momento do cadastro, permitindo o acesso às pessoas no momento em que navegam por diversos sites e deixam seus rastros" (TURCHI, 2018, p. 11). A Web 3.0 consegue organizar e agrupar as páginas por temas, assuntos e interesses que 0 internauta expressa previamente, possibilitando resultados mais coerentes com o que o usuário realmente pesquisa e deseja. Com isso, a forma de se fazer publicidade é alterada em função de novos hábitos, pois "a web 3.0 é um sistema que inclui desde redes sociais, serviços empresariais online até sistemas GPS e televisão móvel, assim como o aumento das etiquetas inteligentes que permitem lidar com a informação de uma forma mais simples" (BARICHELLO et. al., 2013, p. 138).

A capacidade tecnológica é importante, mas a experiência que as máquinas conseguem nos proporcionar é que causa o real impacto e revoluciona a comunicação. Para Chatfield (2012, p.27), "se quisermos conviver com a tecnologia da melhor forma possível, precisamos reconhecer que o que importa, acima de tudo, não são os dispositivos individuais que utilizamos, mas as experiências humanas que eles são capazes de criar". Não existe uma lógica rígida na previsão das ações que serão desenvolvidas para a internet considerando que as ferramentas digitais evoluem diariamente; o que podemos detectar é que o ambiente midiatizado coloca em cena a produção de conteúdo, e a interatividade modifica o fluxo da comunicação. Uma das mudanças mais significativas, segundo 
Recuero (2011), é a possibilidade de expressão e sociabilização por meio de ferramentas de comunicação mediadas pelo computador.

"O que a internet trouxe de mais inovador foi o fato de ter mudado profundamente $\mathrm{o}$ comportamento das pessoas, tirando-as de um estado de passividade e tornando-as mais críticas, exigentes e ativas, ou seja, protagonistas nesse novo cenário junto às marcas" (TURCHI, 2018, p. 72). Com essas informações, é importante que as estratégias considerem o contexto de mudança no comportamento dos consumidores, que atualmente tem muito mais poder e influência, especialmente pela sua inserção nas mídias sociais digitais.

\section{Procedimentos metodológicos}

Esta pesquisa é de abordagem qualitativa, na qual o pesquisador "discute, correlaciona, interpreta situações, fatos, opiniões e conclui valores através de análise coerente" (MICHEL, 2015, p. 44). Quanto aos meios, trata-se de uma pesquisa teórica, que segundo a autora (2015, p. 49) "se propõe a discutir e criticar teorias existentes". Conforme afirma Michel (2015, p. 49), a pesquisa teórica "apoia-se em verdades imperativas, oriundas de estudos anteriores, dispensando a prática e valorizando o uso da razão e da lógica".

Os procedimentos de pesquisa foram os seguintes: a) levantamento de bibliografia; b) seleção das obras consultadas a partir dos critérios de visibilidade acadêmica (autores frequentemente citados em trabalhos da área da comunicação), publicação em livro e em Língua Portuguesa e acesso das pesquisadoras às obras; c) descrição das estratégias de comunicação, estratégias de marketing e estratégias de promoção a partir das obras selecionadas; d) problematização dos conceitos a partir do levantamento feito. Após as etapas de levantamento, seleção e descrição, a discussão foi realizada com base nas teorias de Lupetti (2007), Vaz (2011), Gabriel (2010), Kotler, Kartajaya e Setiawan (2017) e Turchi (2018), dando-se sequência ao trabalho.

\section{Estratégias: perspectivas de um conceito}

A palavra estratégia tem origem grega e relação direta com a arte dos generais de guerra que tinham a vitória como o objetivo mais evidente. Também envolve raciocínio e inteligência que são utilizados frequentemente para a aplicação de procedimentos inesperados a fim de superar a concorrência de alguma forma (PÚBLIO, 2008). 


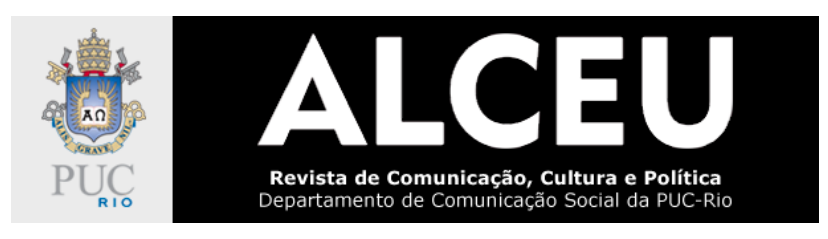

A conceituação a respeito de estratégia é variada, mas, de uma forma ou de outra, culmina remetendo às ações tanto ofensivas quanto defensivas que são tomadas para conquistar alguma vantagem em um campo. Mintzberg (2010, p. 24) acredita que toda estratégia pode ser estudada como "um padrão, isto é, coerência em comportamento ao longo do tempo". Segundo o autor, existem duas situações que se destacam nesse conceito: a estratégia pretendida, que remete aos planos futuros da organização; e a estratégia realizada, ou seja, ações que já foram executadas.

Para que isso ocorra, a estratégia precisa ter relação direta com o ambiente e, assim, servirá como um guia que registra a posição em que o estrategista se encontra, possibilitando mapear da melhor forma, alcançar uma posição superior. Conforme Porter (1986) afirma, o elemento principal de uma estratégia está diretamente relacionado com as atividades específicas da organização, ou seja, as atividades que a empresa consegue desempenhar e que a diferenciam da concorrência. Segundo o autor, uma estratégia precisa estar alinhada com o objetivo principal da organização, já que dará suporte a todas as outras ações que forem desenvolvidas. Dessa forma, a essência da estratégia está na maneira como a organização escolhe realizar suas atividades, e para isso é necessário utilizar táticas ${ }^{2}$ específicas e o escopo no qual irá atuar.

Para Públio (2008), o conhecimento a respeito do macroambiente de atuação deve ser o primeiro passo para qualquer definição das estratégias de uma empresa. Em seguida, o foco deve passar para o microambiente e os objetivos organizacionais de forma geral. Somente após essas etapas concluídas é que serão definidos os objetivos de marketing e de comunicação. Kotler (2003) explica que uma estratégia de marketing consistente não permite que a concorrência consiga copiar os diferenciais da empresa, permitindo, assim, que mantenha a sua vantagem competitiva. Públio (2008, p. 143) reforça que "antes de determinar qual será a estratégia de comunicação é importante definir o objetivo do marketing". Isso ocorre porque o objetivo da comunicação pressupõe que já exista um objetivo de marketing pré-determinado.

Objetivos e estratégias parecem ser semelhantes; todavia, Públio (2008, p. 155) reforça que "as estratégias de comunicação são os caminhos que levarão o anunciante a atingir seu objetivo de comunicação". Ainda segundo o autor, os elementos que integram a estratégia de comunicação

\footnotetext{
2 Entendemos que a estratégia é baseada em objetivos de longo prazo, e a tática consiste na descoberta da melhor ação imediata a seguir.
} 


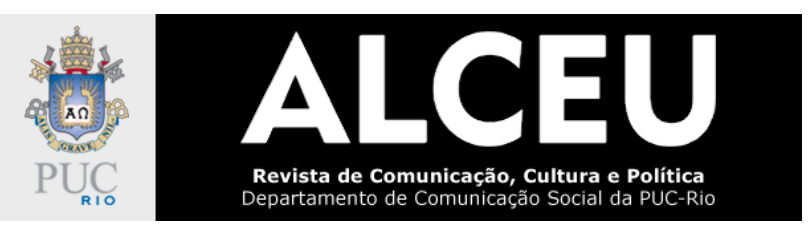

fazem parte de um mix que pode incluir várias ações, como, por exemplo, propaganda, marketing promocional, relacões públicas, venda pessoal, identidade visual e ações na web ${ }^{3}$.

Sabe-se que o contexto atual inclui vários outros elementos; entretanto, o esforço está em demonstrar que o mais importante é realizar uma comunicação que integre todos os setores com sinergia. Ciente de que todos os elementos do mix de comunicação precisam comunicar a mesma informação para os interessados, a próxima etapa implica que "cada elemento constitui uma estratégia, ou um caminho para se atingir o objetivo. Uma vez definidos os caminhos, o próximo passo é definir quais serão as ações para cada estratégia" (PÚBLIO, 2008, p. 160). No entanto,

É preciso reconhecer que a palavra estratégia e sua derivada "estratégica" andam um pouco desgastadas pelo seu uso indevido na literatura e na prática da comunicação empresarial em nosso país. Afinal de contas, depois que as organizações e os gestores descobriram que a expressão "comunicação estratégica" agrega prestígio àqueles que a pronunciam (ainda que não a coloquem em prática), as obras da área e os discursos empresariais estão inundados dela. Mesmo sem saber exatamente o que a expressão efetivamente significa, chefias e até comunicadores passaram a utilizá-la de forma abusiva e ela foi perdendo sentido, porque estava cada vez mais distante do conceito ao qual deveria se referir (BUENO, 2015, p. 124, grifo nosso).

Bueno (2015, p. 125) informa que existem leituras equivocadas na Academia que não consideram o conceito original de estratégia. $O$ autor reforça que as estratégias de comunicação devem refletir "um conjunto de ações de comunicação planejadas que visam atender a determinados objetivos e que, se bem formuladas, implicam metas, ou seja, definem resultados concretos a serem perseguidos". Além disso, todas essas ações têm relação direta com os recursos disponíveis, sejam eles humanos, tecnológicos ou financeiros, e ainda precisam ser conectadas com o ecossistema vigente.

A partir das evoluções tecnológicas, as organizações precisaram adaptar suas estratégias para sobreviver no novo cenário que se instaurou. Evidenciou-se a necessidade de lidar com contextos mais dinâmicos mas, mesmo assim, aplicar uma unidade dentro dos esforços tanto comunicacionais quando de marketing para se criar e manter relacionamento com os consumidores. Entretanto, concordamos com Públio (2008) quando o autor afirma que cada ação deve ser construída de forma específica e relacionada com a sua estratégia direcionadora. Nesse sentido, "pode haver diversas ações para a implementação de uma estratégia, entretanto não pode haver diversas estratégias para a implementação de uma única ação" (PÚBLIO, 2008, p. 161).

${ }^{3}$ Em 2008, Públio já enfatizava a crescente inserção das organizações na web como forma de ampliar suas ações de comunicação. 
Enfatizamos que as características próprias do ecossistema digital precisam estar alinhadas aos objetivos e estratégias de marketing e comunicação pré-determinados de forma geral. Powell, Groves e Dimos (2011, p. 259) chamam atenção para o fato de que a comunicação por meio da internet já é indispensável, e, com base nesse fato, "os profissionais de marketing precisarão fazer suas próprias avaliações de como o futuro se desdobrará e [...] desenvolver as estratégias e táticas de mídia social com as quais consigam gerenciar, medir e lucrar".

\subsection{Quadro conceitual dos tipos de estratégias}

Nesta seção, as fontes selecionadas não se restringem à comunicação, mas abrangem também estratégias de marketing, já que a comunicação encontra-se no "P" de promoção no mix tradicional de marketing (KOTLER, 2003) e, além disso, frequentemente, os trabalhos na área da publicidade costumam analisar as estratégias ora pelo viés das estratégias de comunicação, ora por meio das estratégias de marketing, tanto pela ligação das áreas quanto pela carência de fontes diversas nacionais no campo publicitário.

No ano 2000, Marcélia Lupetti lançou o livro Planejamento de Comunicação, em que sistematizou estratégias de comunicação e suas definições, fornecendo à área um conjunto útil de conceitos que tem sido empregado para nortear o caminho que as empresas de comunicação podem seguir para concretizar suas metas. Desde então, esse conjunto de definições tem sido utilizado também em muitas pesquisas acadêmicas na área da publicidade. A obra já teve outras edições e reimpressões, e seus conceitos foram recuperados em Gestão Estratégica da Comunicação Mercadológica (2007), da mesma autora. As estratégias de campanhas "se referem às ações que deverão ser planejadas e executadas a partir do tipo de campanha escolhida e de determinadas informações" (LUPETTI, 2007, p. 105). O Quadro 2 apresenta os tipos de estratégias.

Quadro 2 - Estratégias de campanhas por Lupetti (2000; 2007)

\begin{tabular}{|l|l|}
\hline Estratégia de informação & $\begin{array}{l}\text { "É caracterizada pela prioridade que dá às informações de um produto ou de uma } \\
\text { empresa. É utilizada, em geral, no lançamento de um produto novo ou inédito, mas } \\
\text { também pode ser usada quando o produto for reformulado ou sofrer alguma } \\
\text { alteração em sua embalagem" (p. 106). }\end{array}$ \\
\hline $\begin{array}{l}\text { Estratégia de testemunho } \\
\text { ou testemunhal }\end{array}$ & $\begin{array}{l}\text { "É bastante aplicada para dar credibilidade ao produto. O uso de celebridades - } \\
\text { atores e atrizes consagrados - pode trazer bom retorno à campanha publicitária" (p. } \\
106) .\end{array}$ \\
\hline $\begin{array}{l}\text { Estratégia de } \\
\text { comparação }\end{array}$ & $\begin{array}{l}\text { "Compara os atributos de um produto aos de seu concorrente. [...] Não ataca o } \\
\text { concorrente, apenas o compara" (p. 106). }\end{array}$ \\
\hline
\end{tabular}




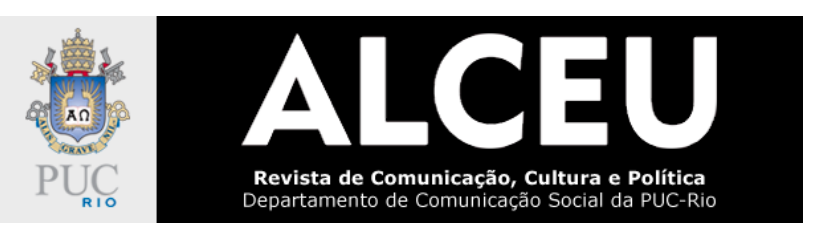

\begin{tabular}{|l|l|}
\hline Estratégia de humor & $\begin{array}{l}\text { "Deve ser usada com muita cautela, uma vez que depende muito do público-alvo a } \\
\text { ser atingido, dos problemas a serem resolvidos na comunicação e do tipo de humor } \\
\text { a ser trabalhado. Embora atraente, essa estratégia pode encobrir o conteúdo } \\
\text { informativo e persuasivo da comunicação, além de cansar o consumidor" (p. 106). }\end{array}$ \\
\hline Estratégia ofensiva & $\begin{array}{l}\text { "Caracteriza-se pela ousadia. Compreende o ataque ao concorrente, visando suas } \\
\text { vulnerabilidades" (p. 106). }\end{array}$ \\
\hline Estratégia de defesa & $\begin{array}{l}\text { "É normalmente usada pelo(s) lídere(s) de mercado com grande posição } \\
\text { competitiva" (p. 107). }\end{array}$ \\
\hline Estratégia indiferenciada & "É recomendada para fixar marcas de empresas ou linhas de produto" (p. 107). \\
\hline $\begin{array}{l}\text { Estratégia de } \\
\text { posicionamento/reposici } \\
\text { onamento }\end{array}$ & $\begin{array}{l}\text { "Você deve associar uma marca a uma palavra na mente do consumidor". Isso } \\
\text { porque as "pessoas não compram produtos. Elas compram uma solução a algum } \\
\text { problema que têm" (p. 107). }\end{array}$ \\
\hline
\end{tabular}

Fonte: Síntese a partir de Lupetti (2007, p. 105-107).

Em 2006, Conrado Adolpho Vaz publicou a obra originalmente chamada de Google Marketing, que, ao longo dos anos, foi reformulada e relançada em 2011 sob o título: Os 8 P's do marketing digital. Segundo o autor, há uma estratégia de marketing digital apoiada no grau de atividade do consumidor, e essa estratégia está dividida em 8 P's, que são os seguintes: pesquisa, planejamento, produção, publicação, promoção, propagação, personalização, precisão. A cada um dos P's, a empresa deve olhar para o mercado, avaliar as ferramentas disponíveis que mais se adaptem à sua meta e, assim, agir. Conforme enfatiza, o essencial é se "apoiar no grau de atividade do consumidor" (VAZ, 2011, p. 300).

Nessa mesma obra, o autor explica que, "de 1980 a 1995, presenciamos as primeiras mudanças em direção a essa nova sociedade - a informatização elevou a níveis nunca antes imaginados o fluxo e a organização da informação" (VAZ, 2011, p. 49). Em decorrência da era da informatização, houve um deslocamento na cadeia produtiva, que migrou da produção de bens para a produção de serviços completamente ligados à informação e ao conhecimento. É dessa forma que o autor introduz outra estratégia de marketing e, englobada aqui, comunicação: a estratégia da encontrabilidade. Nessa perspectiva, "a melhor maneira de encontrar o seu consumidor é ser encontrado por ele" (VAZ, 2011, p. 261): por isso ser encontrado nas primeiras posições dos portais de buscas como o Google é tão importante na era digital, pois "constitui um diferencial competitivo razoável, mas não garante que um consumidor compre de você. É apenas o início da viagem, mas não garante o final dela" (VAZ, 2011, p. 264).

Outra teórica que contribui com o estudo das estratégias é Martha Gabriel, que em 2010 lançou o livro Marketing na era digital, afirmando que "[...] o marketing digital não existe. Existe apenas o marketing, que pode se apropriar das estratégias digitais ou não, em combinação com 
estratégias tradicionais, em função dos objetivos e público-alvo" (GABRIEL, 2010, p. 247). A autora apresenta as seguintes estratégias para serem usadas no ambiente digital (Quadro 3):

Quadro 3 - Estratégias de marketing na era digital para Gabriel (2010)

\begin{tabular}{|l|l|}
\hline $\begin{array}{l}\text { Estratégia de } \\
\text { presença digital }\end{array}$ & $\begin{array}{l}\text { A estratégia de presença digital se divide em três tipos: presença própria, presença gratuita e } \\
\text { presença paga. E o esforço estratégico do comunicador está em "determinar a distribuição de } \\
\text { esforços entre os tipos de presença digital existentes" (p. 250). }\end{array}$ \\
\hline $\begin{array}{l}\text { Estratégia de } \\
\text { conversão nas } \\
\text { landing pages }\end{array}$ & A conversão deve necessariamente resultar em uma ação do consumidor. \\
\hline $\begin{array}{l}\text { Estratégia de e- } \\
\text { mail marketing }\end{array}$ & $\begin{array}{l}\text { "Prática que utiliza eticamente o envio de mensagens por e-mail para atingir os objetivos de } \\
\text { marketing" (p. 261). Ferramenta que começa a ser aplicada como forma de segmentação } \\
\text { para relacionamentos. }\end{array}$ \\
\hline $\begin{array}{l}\text { Estratégia de } \\
\text { mobile marketing }\end{array}$ & $\begin{array}{l}\text { "A mobilidade está relacionada ao acesso constante e disponível, 24 horas durante 7 dias da } \\
\text { semana, que está se tornando realidade" (p. 278). Suas principais características são: } \\
\text { mobilidade, geolocalização, convergência, transmídia (crossmedia), interatividade. }\end{array}$ \\
\hline $\begin{array}{l}\text { Estratégia de } \\
\text { marketing em } \\
\text { mídias sociais }\end{array}$ & $\begin{array}{l}\text { As duas características principais das estratégias de redes sociais são a viralização e o } \\
\text { poder analítico. "A capacidade de viralização do ambiente é importante quando a marca } \\
\text { precisa alcançar e impactar o maior número possível de pessoas. O poder analítico do } \\
\text { ambiente se torna essencial quando uma marca precisa ganhar relevância e credibilidade, } \\
\text { que só são alcançadas com ambientes que propiciem ricas discussões e análises" (p. 296). }\end{array}$ \\
\hline $\begin{array}{l}\text { Estratégia de } \\
\text { marketing de } \\
\text { busca }\end{array}$ & $\begin{array}{l}\text { Pode ser off-page e on-page e serve para "alavancar tráfego e presença on-line" (p. 248). } \\
\text { SEO (Search Engine Optimization) é a estratégia de otimização da página nos sites de } \\
\text { busca, para aparecer de forma melhor ranqueada nas páginas de resultados. Há também a } \\
\text { estratégia de links patrocinados, que decorre "da compra de palavras-chave" (p. 389). }\end{array}$ \\
\hline
\end{tabular}
Fonte: Síntese a partir de Gabriel (2010).

Gabriel (2010) enfatiza que "apesar de as estratégias nas redes sociais digitais serem baseadas no relacionamento humano e em estudos sociais, a tecnologia impacta sensivelmente essas estratégias, pois modifica os modos de relacionamento humano" (p. 344). Essa adaptação das práticas de marketing e comunicação que passam a estar centradas no consumidor também é compartilhada por outros autores. No entanto, segundo afirma Bueno (2015), não basta utilizar as mídias sociais apenas como um espaço de divulgação de assuntos que interessem diretamente à marca, pois isso é insuficiente para ativar a interação. $O$ autor explica que, no cenário brasileiro, o mais praticado é a divulgação desse tipo, e isso desconsidera o potencial amplo dessas plataformas de relacionamento.

Em Marketing 4.0, uma atualização de Marketing 3.0, Philip Kotler, Hermawan Kartajaya e Iwan Setiawan (2017, p. 129) elaboram o que denominam "aplicações táticas de marketing na economia digital", que são aplicações que mais se assemelham a estratégias de marketing para 0 contexto digital contemporâneo. Tais aplicações são as seguintes: marketing centrado no ser humano, marketing de conteúdo, marketing onicanal e marketing de engajamento (Quadro 4). 
Quadro 4 - Aplicações táticas segundo Kotler, Kartajaya e Setiawan (2017)

\begin{tabular}{|c|c|}
\hline $\begin{array}{l}\text { Marketing } \\
\text { centrado no } \\
\text { ser humano }\end{array}$ & $\begin{array}{l}\text { - Diferencia a marca por meio da atribuição de uma personalidade humana. Pode ser desenvolvida } \\
\text { com base em seis atributos originais de Stephen Sampson: fisicalidade (atrativos físicos, como } \\
\text { logotipos ou embalagens especiais, dinâmicos e flexíveis); intelectualidade (inovação da marca); } \\
\text { sociabilidade (comunicação regular com os consumidores por meio de canais de mídias sociais, } \\
\text { conversa menos formal que a aproxima marca e consumidor); emocionalidade (marcas que } \\
\text { evocam emoções no consumidor mediante mensagens emocionalmente envolventes e afetuosas); } \\
\text { personalidade (autoconfiança e autoconsciência da marca sobre o que representam e sobre suas } \\
\text { falhas); moralidade (expressão de valores éticos e morais pela marca). } \\
\text { - Serve para desenvolver atração de marca e influenciar os consumidores como amigos, rompendo } \\
\text { barreiras e gerando proximidade. }\end{array}$ \\
\hline $\begin{array}{l}\text { Marketing de } \\
\text { conteúdo }\end{array}$ & $\begin{array}{l}\text { - "Conteúdo é o novo anúncio, \#hashtag é o novo slogan" (p. 147). } \\
\text { - Consiste em criar, selecionar distribuir e ampliar conteúdo de relevância, interesse e utilidade } \\
\text { para o consumidor. O papel da promoção de marca é mudado para a contação de histórias. O } \\
\text { conteúdo pode ser produzido pela marca ou gerado por fontes externas, desde que distribuído pela } \\
\text { marca por seus canais, geralmente, mídias sociais. } \\
\text { - Serve para gerar conversas no público em torno do conteúdo tornado compartilhado pela marca. }\end{array}$ \\
\hline $\begin{array}{l}\text { Marketing } \\
\text { onicanal }\end{array}$ & $\begin{array}{l}\text { - Consiste na integração de vários canais de venda (praça) e comunicação (promoção), para } \\
\text { atender às demandas do consumidor na era digital. Une estratégias on-line e off-line, tais como } \\
\text { canal de vendas mobile explorado no ponto de venda físico como opção ao consumidor. } \\
\text { - Serve para criar uma experiência de consumo uniforme e contínua, em que o consumidor seja } \\
\text { conduzido à compra. }\end{array}$ \\
\hline $\begin{array}{l}\text { Marketing de } \\
\text { engajamento }\end{array}$ & $\begin{array}{l}\text { - Consiste em investir em técnicas que melhorem o engajamento para conduzir à compra e à defesa } \\
\text { da marca pelos clientes, com foco na experiência digital. Uso de aplicativos para dispositivos } \\
\text { mobile, uso de gestão do relacionamento com o cliente (CRM) e uso de gamificação apresentam- } \\
\text { se como técnicas úteis para gerar engajamento. } \\
\text { - Serve para converter consumidores novos em defensores fiéis da marca. }\end{array}$ \\
\hline
\end{tabular}

Fonte: Síntese a partir de Kotler, Kartajaya e Setiawan (2017)

Em Estratégias de marketing digital e e-commerce, Turchi (2018, p. 151) afirma que as marcas "estão se tornando cada vez mais humanas e personalizadas visando a estabelecer interações e um vínculo emocional mais forte e duradouro". Nesse contexto, as mídias sociais destacam-se, com a ressalva de que não são sinônimos de redes sociais, pois, segundo a autora, se referem "ao meio, ou seja, às ferramentas usadas para comunicação, que incluem as redes sociais e os sites de Internet que permitem a criação e o compartilhamento de informações e conteúdo de pessoas para pessoas" (TURCHI, 2018, p. 141).

Assim, em um cenário que possibilita que consumidores se tornem produtores de conteúdo, são propostas estratégias de marketing digital e e-commerce que atendam às novas demandas, ainda que a autora apresente as definições ao longo do texto, sem realizar uma classificação ou definição sistemática (Quadro 5). 
Quadro 5 - Estratégias de marketing digital e e-commerce de Turchi (2018)

\begin{tabular}{|c|c|}
\hline $\begin{array}{l}\text { Estratégia de } \\
\text { marketing nos } \\
\text { buscadores (SEM e } \\
\text { SEO) }\end{array}$ & $\begin{array}{l}\text { O SEM (Search Engine Marketing) pode se dividir em duas estratégias: busca orgânica } \\
\text { ou natural e busca paga (links patrocinados). Os links patrocinados devem ser usados } \\
\text { como complemento à otimização dos sites. } \\
\text { O SEO (Search Engine Optimization) é utilizado para elevar a posição de um site na } \\
\text { busca orgânica. Isso permitira que um site possa ser "melhor encontrado pelo Google, } \\
\text { sem usar links patrocinados" (p. 82). }\end{array}$ \\
\hline $\begin{array}{l}\text { Estratégia de e-mail } \\
\text { marketing }\end{array}$ & Citada como uma estratégia tradicional. \\
\hline $\begin{array}{l}\text { Estratégia de atuação } \\
\text { focada em } \\
\text { relacionamento }\end{array}$ & $\begin{array}{l}\text { Planejamento nas mídias sociais com base nos objetivos. } \\
\text { "Trabalho integrado entre muitas ações paralelas" (p. 148). } \\
\text { "Disponibilização de conteúdo relevante para o seu público de interesse e, ainda, contar } \\
\text { com a sua participação para criar um conteúdo cada vez mais colaborativo" (p. 148). } \\
\text { Também serve para incentivar novos usos de produtos existentes. \#PreparaPraMim (p. } \\
\text { 149) }\end{array}$ \\
\hline $\begin{array}{l}\text { Estratégia de } \\
\text { reputação digital }\end{array}$ & $\begin{array}{l}\text { "Começa com o que a empresa deseja para sua marca nos médio e longo prazos. Além } \\
\text { disso, as ações na web não podem estar desconectadas das estratégias globais da } \\
\text { empresa; muito pelo contrário, devem caminhar juntas" (p. 148). }\end{array}$ \\
\hline $\begin{array}{l}\text { Estratégia de } \\
\text { inteligência coletiva }\end{array}$ & "Uso do meio digital para captação de oportunidades de inovação" (p. 149). \\
\hline $\begin{array}{l}\text { Estratégia de } \\
\text { monitoramento }\end{array}$ & $\begin{array}{l}\text { Serve para ampliação de negócios/construção de confiança. } \\
\text { "Mudança na postura de algumas empresas na forma como se relacionam com seus } \\
\text { públicos, ouvindo, prestando atenção, respondendo" (p. 149). } \\
\text { "As redes sociais possuem um grande poder de mobilização, fluxo de informações } \\
\text { elevado, e tanto podem beneficiar uma marca como destruí-la" (p. 163). }\end{array}$ \\
\hline $\begin{array}{l}\text { Estratégia de criação } \\
\text { de persona da marca } \\
\text { para redes sociais }\end{array}$ & $\begin{array}{l}\text { "Deve ser pensada até mesmo antes da definição de sua logomarca. Essa persona leva } \\
\text { em conta sua história, características emotivas e físicas, personalidade, valores e ideias } \\
\text { compatíveis } \mathrm{cm} \text { as do seu público-alvo, que poderão ser mudadas com o tempo ao } \\
\text { vivenciar experiências e aprender coisas novas. Ela pode falar em nome da marca" (p. } \\
\text { 151). }\end{array}$ \\
\hline $\begin{array}{l}\text { Estratégia de inbound } \\
\text { marketing (dentro de } \\
\text { marketing de } \\
\text { conteúdo) }\end{array}$ & $\begin{array}{l}\text { "O marketing de conteúdo está intimamente ligado à estratégia de inbound marketing, } \\
\text { que, resumidamente, se baseia na atração dos leads (futuros clientes) através do } \\
\text { fornecimento do conteúdo diversificado e relevante, bem como do acompanhamento } \\
\text { para que se gerem grupos segmentados de acordo com seus interesses; e somente } \\
\text { após algumas etapas, como a de nutrição dos leads, por exemplo, é que será oferecido } \\
\text { algum produto (ou serviço) bastante alinhado com o perfil identificado dos seus } \\
\text { prospects" (p.159). }\end{array}$ \\
\hline $\begin{array}{l}\text { Estratégia de } \\
\text { Storytelling (dentro de } \\
\text { marketing de } \\
\text { conteúdo) }\end{array}$ & $\begin{array}{l}\text { "Uma grande oportunidade para as marcas que querem dialogar com públicos cada vez } \\
\text { mais saturados de informação e, com isso, construir uma estratégia de relacionamento } \\
\text { baseada numa poderosa ferramenta de compartilhamento de conhecimento e emoção" } \\
\text { (p.160) } \\
\text { "O segredo está em atribuir significados emocionais a elementos técnicos por meio de } \\
\text { um contexto relevante, ter um objetivo final e, ainda, trabalhar a curiosidade ao criar } \\
\text { expectativa para que os consumidores queiram saber a continuidade da história e, } \\
\text { assim, aumentar as possibilidades de engajamento e desdobramento" (p. 160). }\end{array}$ \\
\hline $\begin{array}{l}\text { Estratégia de } \\
\text { remarketing }\end{array}$ & $\begin{array}{l}\text { "Redirecionamento comportamental, em que os anúncios são apresentados para } \\
\text { usuários com base em algumas medidas que tomaram no passado recente, como } \\
\text { acesso ao site de uma marca ou a interação com um e-mail marketing" (p. 126). A } \\
\text { vantagem para a empresa é orientar sua estratégia de comunicação com base no } \\
\text { interesse do usuário, conseguindo uma segmentação mais precisa. }\end{array}$ \\
\hline $\begin{array}{l}\text { Estratégia digital } \\
\text { baseada em influência }\end{array}$ & $\begin{array}{l}\text { Baseada na forma como os usuários-mídia se comportam em relação ao seu meio } \\
\text { social. }\end{array}$ \\
\hline
\end{tabular}


Fonte: Turchi (2018).

Além disso, como práticas voltadas para a estratégia de marketing, a autora cita a inteligência social, a cocriação, o crowdsourcing e a gamificação. A inteligência social refere-se ao rastreamento de dados dos usuários para detectar comportamentos de consumo e oportunidades. A cocriação resulta da atividade conjunta entre a empresa e seus clientes, com o objetivo final de gerar negócios que tragam melhores experiências para o consumidor, que participa do processo de inovação. O crowdsourcing também é um modelo de produção de conteúdo que usa a inteligência e o conhecimento coletivo para aprimorar processos centrados no usuário mediante mudanças incrementais. Já a gamificação serve para estimular os participantes por meio de elementos de jogo, como o desafio, a geração de pontos e a recompensa, visando gerar novas experiências (TURCHI, 2018).

Como desafio, há a adequação das estratégias ao contexto e a absorção das novas práticas, já que são distintas da publicidade tradicional. Estratégias como a baseada em influência exploram algo característico das mídias sociais: "a preferência do público é mais voltada para conteúdo de bastidores, original e pouco trabalhado, diferentemente do que ocorre na mídia tradicional" (TURCHI, 2018, p. 177). Dessa forma, é cultivado o interesse que as pessoas têm pela vida cotidiana de celebridades, marcas, influenciadores e empresas.

De modo geral, as estratégias na ambiência digital servem para expandir os horizontes do marketing tradicional e, portanto, devem estar alinhadas à estratégia global da empresa. Segundo Turchi (2018, p. 172) "o uso de mídias sociais para ampliação dos relacionamentos tem sido um movimento crescente em todos os países, principalmente nos emergentes". A autora ainda enfatiza que não podemos ignorar a revolução que a web acarretou no comportamento humano, já que "impacta a maneira como as pessoas se relacionam umas com as outras, ou com as empresas e com o consumo" (TURCHI, 2018, p. 172). Sem citar a palavra estratégia, a autora também lembra que "é importante entender que a agilidade na criação e publicação de conteúdos de acordo com o assunto do momento é fundamental para obter bons resultados nas redes sociais e blogs" (TURCHI, 2018, p. 177). Esse processo é definido como real time marketing ou marketing de oportunidade, o que pode ser compreendido como outra estratégia ou um desdobramento do marketing na ambiência digital.

Nesse sentido, para Turchi (2018), no novo cenário, é necessário criar estratégias que consigam aproveitar todos os benefícios que a comunicação pode gerar e, para tanto, é importante: ter timing, isto é, um tempo de resposta condizente com o que o público espera; conhecer que canais 


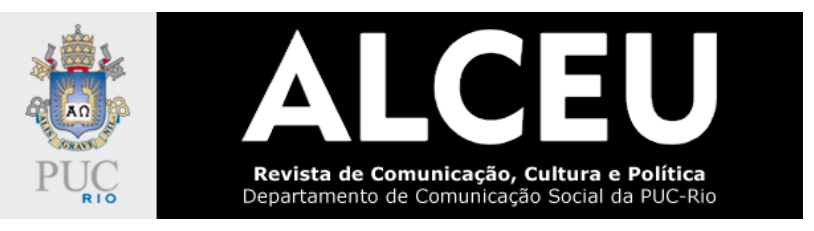

devem ser priorizados para cada estratégia; trabalhar com equipes multidisciplinares; perceber que estabelecer relacionamentos com as pessoas é mais vantajoso do que obter seguidores; criar conteúdo interessante para os usuários e as marcas; ter transparência, o que é fundamental no mundo digital e conectado. Por fim, deve ser considerada também a necessidade de abrir espaço para a inclusão, considerando a diversidade.

Essas foram as estratégias consultadas, que seguem sendo utilizadas nos estudos na área da publicidade. Como se pode constatar, não há uma terminologia unificada; há diferentes definições que, em alguns casos, se assemelham e coincidem, mas que, ainda que sejam definições úteis, necessitam de uma melhor sistematização e correlação com o contexto digital contemporâneo, já que alguns dos conceitos remontam ao início dos anos 2000.

\section{Problematizações}

No cenário atual, são tantas as possibilidades de ação para as marcas que não há uma sistematização ainda pronta, conforme observamos nas obras deste levantamento. Nas estratégias formuladas por Vaz (2011), observamos que o autor apresenta procedimentos de marketing, tais como pesquisa e planejamento, como estratégias e, nesse amplo quadro de definições, destaca a estratégia de marketing digital e, também, a estratégia que denomina como encontrabilidade. Isso ocorre porque sua tese é fundamentada em uma análise do Google e de seus mecanismos de busca, a fim de compreender como auxiliam as marcas.

A obra do autor destaca-se por enfatizar as mudanças no marketing em geral trazidas pela informatização da sociedade, o que modificou todo o fluxo de informações. Se, por um lado, foram preservadas práticas de marketing que sustentam as ações da empresa, como pesquisa e planejamento, por outro lado, deslocou-se o centro da cadeia de produção, que passou a ser o consumidor, na medida em que fornece informações para a empresa e, assim, participa cada vez mais ativamente dos processos (VAZ, 2011).

Na perspectiva de Gabriel (2010), não há uma especificidade no campo, ou seja, o marketing permanece como uma filosofia empresarial única, sem classificar-se em digital ou tradicional. A especificidade das práticas deve-se, assim, às estratégias, que são realizadas tanto no ambiente digital quanto no tradicional. Ainda assim, os tipos de estratégias apresentados por Gabriel (2010) provocam sobreposições que, na prática, podem ser pouco didáticas nas definições, a exemplo das estratégias nomeadas como presença digital, mobile marketing, e-mail marketing, conversão nas 
landing pages e estratégias de marketing em mídias sociais. Por definição, todas essas estratégias podem se enquadrar, também, como estratégias em mídias sociais, outra classificação utilizada pela autora, pois se tratam de ações específicas para atender a determinado objetivo, ou seja, confundem-se com ações táticas devido a sua especificidade. O e-mail, por exemplo, é um canal de contato que pode ser utilizado para diferentes estratégias de marketing, inclusive pela estratégia de marketing de conteúdo, assim como a landing page.

Kotler, Kartajaya e Setiawan (2017) trazem para a discussão a evolução do conceito de marketing, que iniciou centrado no produto (marketing 1.0), passou a se concentrar no consumidor (marketing 2.0) e evoluiu para a centralização no ser humano (marketing 3.0), em consonância com a evolução dos cenários da Web. Os autores explicam que, com a digitalização do contexto, será cada vez mais importante a centralidade humana aliada à humanização também das marcas (marketing 4.0). Isso sugere que "as marcas precisam demonstrar atributos humanos capazes de atrair consumidores e desenvolver conexões de pessoa a pessoa" (KOTLER; KARTAJAYA; SETIAWAN, 2017, p. 134). Os autores indicam que o marketing digital e o marketing tradicional serão unidos em função da convergência tecnológica e salientam que "o marketing deve se adaptar à natureza mutável dos caminhos do consumidor na economia digital" (KOTLER; KARTAJAYA; SETIAWAN, 2017, p. 12).

Um aspecto a observarmos é que os autores não citam estratégias de marketing, e sim táticas, ou seja, modos de ação específicos que orientam as decisões das empresas. Além disso, uma tática está relacionada a outra, como no caso das táticas centradas no ser humano, que geram atração de marca, aliadas ao marketing de conteúdo, que gera curiosidade para a marca; na sequência, o marketing onicanal, que gera compromisso com a marca, e o marketing de engajamento, que gera afinidade. Assim, todas as táticas apresentadas pelos autores se conectam e complementam em uma grande estratégia de humanização de marca, que, por sua vez, tem relação direta com o comportamento do consumidor.

Alinhada ao pensamento de Kotler, Sartajaya e Setiawan (2017), Turchi (2018) considera que a humanização das marcas e o consumidor como ponto central das estratégias tendem a se fortalecer no cenário digital. Segundo a autora, as estratégias precisam levar em conta a mudança de atitudes dos consumidores, que atualmente têm mais poder e influência, especialmente pela sua inserção nas mídias sociais. Para tanto, cita ações que as empresas e marcas podem 
desempenhar na ambiência digital e as nomeia como "estratégias no mundo digital" (TURCHI, 2018, p. 72).

As estratégias ainda são recentes e estão em constante evolução; portanto, a autora salienta que existe espaço para inovações, que precisam ser testadas. Para o profissional, muda, inclusive, a forma de analisar resultados, que não podem mais se restringir a aspectos qualitativos, mas também quantitativos gerados constantemente pelas ferramentas de marketing digital (TURCHI, 2018).

Enfatiza-se, assim, a necessidade de planejamento e pesquisa para entender quais são as ações mais adequadas para cada tecnologia e meios digitais, que se mostram favoráveis a estratégias digitais específicas. Como as mídias sociais são canais propícios para criar e estreitar relacionamentos, isso "deve ser feito por meio da publicação de informações do interesse daquele público determinado" (TURCHI, 2018, p. 157). Assim, segundo afirma, é preciso trabalhar o 4 Cs das mídias sociais: conteúdo, colaboração, comunidade e inteligência coletiva. Entretanto, identificamos que, além de estratégias nomeadas pela autora, há ações e instrumentos citados, ora como ferramentas, ora como estratégias, como é o caso do e-mail marketing.

Considerando o exposto, é importante entender que a interação e as possibilidades oferecidas pela tecnologia são responsáveis por várias mudanças que as práticas publicitárias sofreram no período em que o corpus deste projeto foi analisado. A partir desse contexto, destacamos três problematizações principais.

A primeira delas é que, a partir da literatura consultada, não há um padrão de termos nas definições dos tipos de estratégias de comunicação, ou seja, aquilo que é tratado como estratégia de comunicação, por diversas vezes, aparece misturado com estratégias de marketing que se voltam para outros P's do mix de marketing, tal como a estratégia de marketing nos buscadores (SEM e SEO) de Turchi (2008), que se refere a um dos usos da inteligência e da tecnologia para otimização de sites e mídias, sem, contudo, estabelecer a comunicação direta com o usuário.

A segunda problematização é que não há clareza suficiente em alguns conceitos e definições, como na estratégia indiferenciada de Lupetti (2007), cuja definição de fixar marcas e linhas de produtos é pouco esclarecida e pode se confundir com a estratégia de posicionamento ou reposicionamento, por exemplo. Além disso, nos modelos de Gabriel (2010), Vaz (2011) e Turchi (2018) há pouca didatização dos conceitos, que se encontram ao longo dos textos ora declaradamente como estratégias, ora como práticas ou ferramentas. 


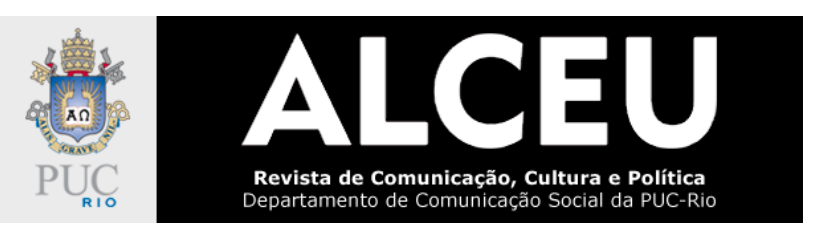

A terceira problematização é o fator a ser destacado neste trabalho, que se refere à carência de estratégias que sejam suficientes para caracterizar especificamente a comunicação na ambiência digital, isto é, estratégias de comunicação para a era digital. Isso se deve ao fato de que, assim como a comunicação é produto de uma evolução, os meios modificaram as formas de comunicação, provocando a elaboração e reelaboração das estratégias de comunicação. Fala-se em criar conteúdo, estabelecer relacionamentos, conhecer o consumidor; entretanto, não se coloca com clareza quais são as estratégias existentes e quais são as ações necessárias para alcançálas, isto é, as táticas.

Apenas na obra de Lupetti (2007), que é a mais antiga das referências consultadas, foi encontrada uma sistematização didática das estratégias, enquanto Kotler, Kartajaya e Setiawan (2017) sistematizam claramente táticas. Considerando os tipos de estratégias de comunicação elencados por Lupetti (2007), averiguamos que todas as estratégias estão classificadas conforme o conteúdo da campanha ou peça publicitária, ou seja, a classificação é feita a partir do que se observa no teor das mensagens. Assim, uma mesma mensagem pode fazer uso de mais de uma estratégia, pois não são excludentes, a exemplo da estratégia de informação, que pode estar presente juntamente com qualquer outra estratégia determinada pela autora. Públio (2008) explica a complementaridade entre as estratégias, pois, conforme afirma, os elementos do mix de marketing, ainda que estejam apresentados independentemente, estão inter-relacionados na prática. Dessa maneira, não existem estratégias realizadas isoladamente, mas em conjunto umas com as outras.

\section{Reflexões finais}

Segundo a análise realizada, a obra que oferece uma sistematização dos conceitos e uma classificação das estratégias de comunicação, sem confundi-las com estratégias de marketing ou táticas, é a referência mais antiga dentre as consultadas, que não dá conta das possibilidades de ação especificamente do contexto digital e de todo o seu cenário de transformação. No cenário contemporâneo, marcas e empresas não podem mais seguir modelos de comunicação convencionais, que visam ao consumidor como público-alvo amplo e distante. As comunicações são pessoalizadas, personalizadas e precisam criar vínculos significativos. Por essa razão, marcas e empresas necessitam detectar comportamentos e, para tanto, utilizam cada vez mais ferramentas 
de rastreio, para fornecer soluções e conteúdos relevantes. O relacionamento é tão intenso que, conforme administrado, pode resultar na cocriação de produtos e inovações.

A partir das reflexões, consideramos que as estratégias não podem se situar no mesmo nível das ações que são utilizadas na sua construção e atuam para atingir o mesmo objetivo. Por essa razão, detectamos a necessidade de um trabalho de elaboração de um quadro teórico de estratégias de comunicação próprias para a ambiência digital. Um fato que ficou claro é que as estratégias de comunicação administram a informação de três formas diferentes, a saber: elas oferecem a informação, solicitam a informação ou trocam informações com os consumidores. No primeiro caso, oferecem a informação quando utilizam as mídias como um espaço de veiculação de conteúdo, por exemplo. E na ambiência digital o importante é pensar nesse fornecimento de forma a aproveitar as oportunidades do meio, entender como e onde otimizar a oferta dessa informação, e não agir apenas de modo equivalente ao que já era feito na ambiência tradicional. O segundo caso é quando solicitam a informação, para ampliar o banco de dados e conhecer mais os consumidores com os quais precisam estabelecer contato para chegar ao terceiro caso, que é o da troca de informação.

A troca de informação é a principal característica da comunicação no cenário digital, pois rompe com a unilateralidade da comunicação convencional. Os conteúdos e as mensagens podem partir da base para o topo, ou seja, dos consumidores para as marcas. As marcas, por sua vez, podem aproveitar esse potencial na geração de conteúdo realmente relevante do ponto de vista do consumidor e, inclusive, podem detectar oportunidades de inovação em produtos.

A escolha de qual tipo de uso da informação deve ser utilizado em cada momento direcionará a estratégia de comunicação, e isso tem relação direta com o objetivo de cada organização estabelecido pelo marketing. Nesse sentido, as mídias digitais precisam estar presentes e alinhadas com todas as formas de ação da empresa, como um esforço de comunicação integrada; caso contrário, se pulverizam mediante tantas possibilidades de uso das ferramentas. Por fim, se há ferramentas (plataformas e dispositivos) tecnológicas que são próprias do cenário atual de comunicação, também deve haver uma sistematização de estratégias próprias a essa ambiência, para que sejam compreendidas e utilizadas.

Taís Steffenello Ghisleni Professora na Universidade Franciscana (UFN) Doutora em Comunicação / UFSM ORCID: https://orcid.org/0000-0002-5405-9492 E-mail: taisghisleni@yahoo.com.br 
Graziela Frainer Knoll

Professora na Universidade Franciscana (UFN)

Doutora em Linguística / UFSM

ORCID: https://orcid.org/0000-0002-6014-2188

E-mail: grazifk@yahoo.com.br

Recebido em: 24 de setembro de 2019.

Aprovado em: 9 de outubro de 2019.

\section{Referências}

BARICHELLO, Eugênia Maria Marino da Rocha et. al. Estendendo as práticas de Relações Públicas sob a perspectiva teórica da ecologia das mídias. In: RUBLESCKI, Anelise; BARRICHELLO, Eugenia Mariano da Rocha. (Orgs.) Ecologia da Mídia. Santa Maria: FACOS-UFSM, 2013. p.129-154.

BUENO, Wilson da Costa. Comunicação empresarial: teoria e pesquisa. São Paulo: Manole, 2003.

Estratégias de comunicação para as mídias sociais. In: BUENO, Wilson da Costa (org.). Estratégias de Comunicação nas Mídias Sociais. São Paulo: Manole, 2015. p. 123-144.

CHATFIELD, Tom. Como viver na era digital. Trad: Bruno Fiuza. Rio de Janeiro: Objetiva, 2012.

GABRIEL, Martha. Marketing na era digital: conceitos, plataformas e estratégias. São Paulo: Novatec Editora, 2010.

KOTLER, Philip. Marketing de A a Z: 80 conceitos que todo profissional precisa saber. Rio de Janeiro: Elsevier, 2003.

KOTLER, Philip; KARTAJAYA, Hermawan; SETIAWAN, Iwan. Marketing 4.0: do tradicional ao digital. Rio de Janeiro: Sextante, 2017.

LUPETTI, Marcélia. Planejamento de Comunicação. São Paulo: Futura, 2000.

. Gestão Estratégica da Comunicação Mercadológica. São Paulo: Thompson Learning, 2007.

McMILLAN, Sally J., Exploring models of interactivity from multiple research traditions: users, documents and systems". In Leah A. Lievrouw, Sonia Livingstone (org.), Handbook of New Media. Social Shaping and Consequences of ICTS, London, Sage, 2002. Disponível em: <http://sk.sagepub.com/reference/hdbk_newmedia/n12.xml> Acesso em: 29 jun. 2016.

MICHEL, Maria Helena. Metodologia e Pesquisa Científica em Ciências Sociais. 3.ed. São Paulo: Atlas, 2015.

MINTZBERG, Henry. Safári de estratégia: um roteiro pela selva do planejamento estratégico. 2. ed. Porto Alegre: Bookman, 2010.

POWELL, G. R.; GROVES, S. W.; DIMOS, J. Retorno sobre o investimento em mídias sociais: como definir, medir e avaliar a eficácia das redes sociais. Rio de Janeiro: Campus, 2011. 
PORTER, Michael. Estratégia competitva. Rio de Janeiro: Elsevier, 1986.

PÚBLIO, Marcelo Abílio. Como planejar e executar uma campanha de propaganda. São Paulo: Atlas, 2008.

RECUERO, Raquel. Redes sociais na internet. 2. Ed. Porto Alegre: Sulina, 2011.

SAAD, Elizabeth. Estratégias 2.0 para a mídia digital. 2.ed. São Paulo: SENAC, 2008.

STRAUSS, Judy; FROST, Raymond. E-marketing. 6.ed. São Paulo: Pearson Prentice Hall, 2011.

STRUTZEL, Tércio. Presença digital: estratégias eficazes para posicionar sua marca pessoal ou corporativa na web. Rio de Janeiro: Alta Books, 2015.

THOMPSON, John B. A mídia e a modernidade. Uma teoria social da mídia. Petrópolis: Vozes, 2008.

TURCHI, Sandra R. Estratégias de marketing digital e e-commerce. 2.ed. São Paulo: Atlas, 2018.

VAZ, Conrado Adolpho. Os 8 Ps do marketing digital: o seu guia estratégico de marketing digital. São Paulo: Novatec, 2011.

\section{Resumo}

A comunicação na ambiência digital se caracteriza pela interação e pela interatividade, que são responsáveis por várias mudanças nas práticas publicitárias ao longo do tempo. Entretanto, frequentemente, os trabalhos na área da publicidade costumam analisar as estratégias ora pelo viés das estratégias de comunicação, ora por meio das estratégias de marketing, tanto pela ligação das áreas, quanto pela carência de fontes diversas nacionais no campo publicitário. Este trabalho de pesquisa teve como objetivo discutir a respeito das estratégias de comunicação existentes centradas na ambiência digital. Como objetivos específicos, foram realizados o mapeamento do quadro conceitual de estratégias de comunicação e de marketing e a problematização da necessidade da atualização de conceitos nessa área. Para tanto, utilizamos pesquisa exploratória e descritiva, partindo dos conceitos de estratégias de comunicação e de marketing ou promoção de autores basilares. Assim, as estratégias foram identificadas, descritas e problematizadas no trabalho a seguir.

Palavras-chave: Comunicação. Ambiência Digital. Estratégia. Tática. Mídia social.

\section{Abstract}

Communication in the digital environment is characterized by interaction and interactivity, which are responsible for several changes in advertising practices over time. However, the work in the advertising field is often used to analyze the strategies either for the bias of communication strategies, or through marketing strategies, both for linking the areas and for the lack of diverse national sources in the field of advertising. This research aimed at discussing the existing communication strategies focused on the digital environment. As specific objectives, the mapping of the conceptual framework of communication and marketing strategies and the problematization of the need to update concepts in this area were carried out. For this, we use exploratory and descriptive research, starting from the concepts of communication strategies and marketing or promotion of basic authors. Thus, the strategies were identified, described and problematized in the following work.

Keywords: Communication; Digital ambience; Strategies. Tactic. Social media 


\section{Resumen}

La comunicación en el entorno digital se caracteriza por la interacción y la interactividad, que son responsables de varios cambios en las prácticas publicitarias a lo largo del tiempo. Sin embargo, el trabajo en el campo de la publicidad a menudo se utiliza para analizar las estrategias, ya sea por el sesgo de las estrategias de comunicación, o por medio de estrategias de marketing, tanto para vincular las áreas como por la falta de diversas fuentes nacionales en el campo de la publicidad. Esta investigación tuvo como objetivo discutir las estrategias de comunicación existentes centradas en el entorno digital. Como objetivos específicos, se llevó a cabo el mapeo del marco conceptual de las estrategias de comunicación y marketing y la problematización de la necesidad de actualizar los conceptos en esta área. Para ello, utilizamos investigaciones exploratorias y descriptivas, comenzando por los conceptos de estrategias de comunicación y marketing o promoción de autores básicos. Por lo tanto, las estrategias se identificaron, describieron y problematizaron en el siguiente trabajo.

Palabras clave: Comunicación. Ambiente digital. Estrategias. Táctica. Redes sociales. 